\title{
Oficinas de teatro como recurso terapêutico ocupacional em um serviço residencial terapêutico*
}

\section{Theater workshops as therapeutic occupational possibility in a therapeutic residential service}

\author{
Meire Luci da Silva ${ }^{1}$, Thaís Munholi Raccioni ${ }^{2}$
}

http://dx.doi.org/10.11606/issn.2238-6149.v26i2p267-273

Silva ML, Raccioni TM. Relato de experiência: oficinas de teatro como recurso terapêutico ocupacional em um serviço residencial terapêutico. Rev Ter Ocup Univ São Paulo. 2015 maio-ago.;26(2):267-73.

RESUMO: Esta pesquisa objetivou investigar as potencialidades do uso terapêutico do teatro como recurso de intervenção terapêutica ocupacional na reinserção social dos usuários de um Serviço Residencial Terapêutico localizado no interior paulista. Para a coleta de dados foram realizadas oficinas teatrais semanais de aproximadamente uma hora, por seis meses, com dezenove moradores. As oficinas basearam-se na técnica do Teatro do Oprimido e nos jogos teatrais de Viola Spolin. Os dados foram registrados em áudio, diário de campo e fotografia, e a análise, baseada na análise temática do conteúdo. Concluiu-se que as oficinas de teatro constituíram espaços de distanciamento da rotina institucional, provocando os sujeitos a se apropriarem de sua potência criativa e conduzindo à redescoberta de si mesmos e de outras possibilidades de reinserção social. As oficinas teatrais afirmaram sua potencialidade ao possibilitar que os sujeitos experimentassem e (re)inventassem modos de produção de vida, bem como desenvolvessem estratégias para lidar com as dificuldades cotidianas.

DESCRITORES: Terapia ocupacional; Serviços de assistência domiciliar; Saúde mental.
Silva ML, Raccioni TM. Theater workshops as therapeutic occupational possibility in a therapeutic residential service. Rev Ter Ocup Univ São Paulo. 2015 May-Aug.;26(2):267-73.

ABSTRACT: This study aimed to investigate the potential of therapeutic use of theater as an occupational therapy intervention resource in the social reinsertion of the users of a Therapeutic Residential Service located in the countryside of São Paulo state. Weekly theatrical workshops with the duration of approximately one hour were conducted for six months with nineteen residents. The workshops were based on the technique of the Theater of the Oppressed and on the theater games of Viola Spolin. Data were recorded on audio, field journal and photography, and a thematic content analysis was performed. It was concluded that the theater workshops constituted distancing spaces of institutional routine, causing the subject to take ownership of their creative power and leading to the rediscovery of themselves and of other possibilities of social reintegration. Theatrical workshops asserted their potential by allowing the subjects to experience and (re)invent life production modes, as well as develop strategies to deal with everyday difficulties.

KEYWORDS: Occupational Therapy; Home care services; Mental health.

\footnotetext{
* Este trabalho foi parte integrante do Trabalho de Conclusão de Curso: Raccioni T M. O teatro como possibilidade estético-terapêutica junto a moradores de um serviço de residência terapêutica. 2012. Universidade Estadual Paulista "Júlio de Mesquita Filho", UNESP, Marília, SP, Brasil.

Trabalho apresentado no XIII Congresso Brasileiro de Terapia Ocupacional, Florianópolis/Santa Catarina em 13 a 16 de outubro de 2013.

1. Professora Assistente Doutora do curso de graduação em Terapia Ocupacional da Faculdade de Filosofia e Ciências da Universidade Estadual Paulista "Júlio de Mesquita Filho", UNESP, Marília, SP, Brasil.

2. Terapeuta Ocupacional, Residente do Programa Multiprofissional em Saúde Mental da Faculdade de Medicina de Marília - FAMEMA, Marília, SP, Brasil.

Endereço para correspondência: Av. Hygino Muzzi Filho, 737, Bairro: Mirante, Marília, SP. CEP: 17.525-000. E-mail: meire@marilia.unesp.br; thaisinha210@hotmail.com
} 


\section{INTRODUÇÃO}

$\mathrm{A}$ s décadas de 1970 e 1980 no Brasil foram marcadas pelo fortalecimento da luta dos movimentos sociais pelo fim da ditadura militar e por direitos democráticos. A Reforma Sanitária e a Reforma Psiquiátrica provocaram profundas mudanças na concepção de saúde e de organização da assistência, tendo como conquista a atual Política Nacional de Atenção em Saúde Mental ${ }^{1}$.

As experiências de desinstitucionalização e criação de serviços abertos deram base à construção do novo modelo assistencial, formado por uma rede de serviços abertos (1989). Na década de 2000, a partir do Decreto Presidencial $n^{0} 7508 / 201$, a Rede de Atenção Psicossocial (RAPS) tornase indispensável na efetivação da atenção à saúde mental ${ }^{2}$.

$\mathrm{Na}$ discussão de alternativas e soluções para a superação do modelo manicomial, emergem questões referentes aos usuários provenientes de longas internações que perderam seus vínculos familiares e sociais e/ou que não possuem imediatamente condições para retomar a vida em sociedade com autonomia ${ }^{3}$. Para tanto, surge como estratégia de atenção a esses usuários os Serviços Residenciais Terapêuticos (SRT), instituídos pela portaria/GM n ${ }^{\circ} 106 / 2000$ MS4. Os SRTs constituem-se em moradias vinculadas a serviços ou equipes de saúde mental de referência e devem ser integradas à rede pública de serviços de saúde, tendo como principais diretrizes: "garantir o convívio social, a reabilitação psicossocial e o resgate de cidadania do sujeito, promovendo os laços afetivos, a reinserção no espaço da cidade e a reconstrução das referências familiares"4.

Os serviços de saúde substitutivos são considerados por Rotelli $^{5}$ como intermediários do processo de desinstitucionalização e, nesta perspectiva, as intervenções realizadas não devem ter mais como foco central de suas intervenções a cura, mas o auxilio na reconstrução das subjetividades, muitas vezes perdidas pela institucionalização ${ }^{5}$.

A concepção de Rotelli ${ }^{5}$ referente ao processo de desinstitucionalização se entrelaça com a Terapia Ocupacional ao perceber o sujeito da atenção como um todo complexo, construído histórica e socialmente, sem reduzi-lo ao seu sofrimento psíquico e reconhecendo-o em suas potencialidades. Sendo assim, ambos propõem intervenções terapêuticas e de atenção direcionadas ao resgate da autonomia e participação social ${ }^{5}$.

Ao descrever o processo terapêutico ocupacional, Francisco ${ }^{6}$ ressalta a importância das atividades humanas significativas como espaços de produção e transformação humana.
Dentre as possibilidades de recursos terapêuticos ocupacionais, considera-se que as artes, dentre estas o teatro, possuem grande importância para o fortalecimento do protagonismo dos sujeitos que a experimentam, propiciando ao sujeito experimentações de si e do outro, bem como o próprio modo de existir e suas possibilidades ${ }^{7}$.

Nesse sentido, este trabalho teve como objetivo investigar as potencialidades do uso terapêutico do teatro como recurso de intervenção terapêutica ocupacional na reinserção social dos usuários de um Serviço Residencial Terapêutico. Ressalta-se que esta pesquisa é fruto do trabalho de conclusão de curso realizado por uma graduanda do curso de Terapia Ocupacional.

\section{Aspectos éticos}

O projeto foi aprovado pelo Comitê de Ética em Pesquisa da Faculdade de Filosofia e Ciências, UNESP - Marília, sob o ${ }^{\circ} 0522 / 2012$. Os participantes foram devidamente informados quanto à pesquisa e, após concordância, assinaram o Termo de Consentimento Livre e Esclarecido.

\section{Cenário do estudo}

O SRT onde foi desenvolvido este trabalho localiza-se em uma cidade do interior paulista. Destaca-se que esse serviço atualmente é gerenciado por um hospital psiquiátrico, contrastando com a Política Nacional de Saúde Mental.

O serviço acolhe dezenove usuários, dos quais quinze se identificam como pertencentes ao gênero feminino e quatro, ao gênero masculino, com idade média de 35 anos e seis meses. Todos os usuários possuem diagnósticos de transtornos mentais crônicos e apresentam trajetória institucional com mais de dez anos de vivência em instituições fechadas, sendo dezoito usuários egressos do mesmo hospital que gerencia o SRT.

\section{PROCEDIMENTOS METODOLÓGICOS}

Trata-se de uma pesquisa de abordagem qualitativa e caráter participante. As percepções e reflexões da pesquisadora foram consideradas relevantes e comparadas às dos participantes. Portanto, buscou-se apreender os aspectos subjetivos vinculados à realidade social em que se desenvolveu o trabalho $0^{8,9}$.

Após a explicação do projeto de pesquisa e realizados os esclarecimentos necessários, foi entregue 
pessoalmente a cada usuário um convite personalizado. O conteúdo foi lido para aqueles que não eram alfabetizados.

Foram desenvolvidas oficinas de teatro semanais, durante seis meses, com duração média de uma hora, em espaços do próprio SRT ou esporadicamente, em uma sala de atendimentos grupais de TO, cedida pelo hospital psiquiátrico que gerencia o serviço e localizada próximo ao SRT. As oficinas foram norteadas pelas técnicas do Teatro do Oprimido desenvolvidas pelo teatrólogo Augusto Boal e jogos teatrais propostos pela educadora norte-americana Viola Spolin ${ }^{10-13}$.

Os registros da elaboração e do desenvolvimento das oficinas foram sistematizados em fichas de planejamento propostas por Spolin (p. 25$)^{10}$, registros em áudio, fotografias e diário de campo.

A fim de compreender as motivações dos usuários para participação ou não nas oficinas foi realizada uma entrevista aberta individual partindo da questão: "Você gostaria de participar das oficinas de teatro? Por quê?" Para identificar a percepção dos usuários em relação às vivências realizadas foi aplicada outra entrevista aberta individual no final do trabalho, com a seguinte questão: "O que você achou das oficinas de teatro?". Os registros foram analisados e interpretados com base no método de Análise Temática de Conteúdo. A sistematização dos conteúdos dos registros constituíram núcleos de sentido, cuja presença e frequência têm significado para o objeto analisado ${ }^{9}$. A partir da análise dos dados emergiram como resultados as categorias explanadas a seguir.

\section{RESULTADOS}

Foram consideradas participantes ativas e diretas oito mulheres e um homem, sendo que todos os usuários participaram esporadicamente ou de forma indireta e o número de participantes em cada oficina oscilou entre quatro e doze usuários.

Para melhor compreensão dos dados, ressalta-se que a identificação dos participantes se deu por meio das iniciais de seus nomes e da pesquisadora, pela letra P. Para a apresentação dos resultados considerou-se a entrevista inicial como ponto de partida, seguindo para as categorias relativas aos aspectos observados e desenvolvidos durante as oficinas. Posteriormente são apresentados aspectos gerais do processo de construção dos personagens e da apresentação final. Para concluir, são apresentados os resultados das entrevistas finais referentes à expressão de sentimentos e opiniões dos usuários sobre o trabalho de modo geral.
A partir da análise dos conteúdos em consonância com o objetivo do estudo, emergiram seis categorias referentes aos aspectos observados durante o processo de trabalho, sendo estas: Falta de iniciativa, participação e vínculo; Compreensão e elaboração do pensamento; Envolvimento e concentração do grupo; Expressão corporal; Processo de construção coletiva e apresentação final.

\section{Entrevistas iniciais}

As entrevistas iniciais foram respondidas por dezenove usuários. Dentre as respostas, houve questionamentos quanto à proposta $\mathrm{e}$ ao grau de dificuldade das atividades que seriam desenvolvidas e também sobre o que é Teatro. Para suprir essas dúvidas, realizou-se um jogo teatral que propiciou a experimentação e reflexão sobre o assunto, no qual concluíram que o teatro é um meio de contar histórias. Durante o jogo teatral foram observados sentimentos como insegurança e resistência por parte de alguns usuários em relação à participação.

\section{Falta de iniciativa, participação e vínculo}

A insegurança da maioria dos participantes em experimentar, em se expor e ter iniciativa ficou evidente. Em alguns momentos, a expressão "não sei" era reproduzida de forma mecânica, refletindo e reforçando a insegurança das participantes em experienciar o que lhes parecia novo, gerando também angústias. Esse fato não foi explicitado por A., que destacou-se ao auxiliar na mediação do grupo, principalmente em relação à falta de iniciativa dos demais participantes, o que fica evidente em sua fala:

\section{A.: Vamo, gente! Não pode conversar na hora que tá fazendo o ensaio. Fica falando: faz isso, faz aquilo, não pode, senão fica feio.}

No decorrer do trabalho foi possível observar que alguns participantes passaram a se colocar mais ativamente, por exemplo, quando R. começou o alongamento inicial antes que lhe fosse solicitado.

Os questionamentos dos usuários frente às propostas de novas experimentações corporais também refletiram sentimento de angústia, fato que pôde ser percebido na realização do jogo Caminhada pelo Espaço ${ }^{7}$. Durante este jogo, O. permaneceu paralisada, referindo estar nessa posição por não saber caminhar arrastando os pés. Como estratégia de enfrentamento dessa dificuldade, foi proposto que a participante e pesquisadora experimentassem juntas 
o caminhar, o que foi relatado por O. como uma experiência difícil, porém agradável.

Ao confrontar discursos e fazeres mecanizados com a possibilidade objetiva de experimentar e criar, os participantes saíam da zona de conforto e acomodação referente ao estigma da loucura internalizado. Incentivar, motivar o grupo e explicitar a potencialidade de cada participante se mostraram fundamentais para começar a desconstruir tal discurso.

Ao longo das oficinas, os diálogos compartilhados passaram a permear histórias de vida, angústias e questionamentos sobre consequências da institucionalização. Também foram observadas expressões de singularidades e particularidades por meio do fazer teatral.

Ao estabelecerem compromissos e assumirem responsabilidades em relação às oficinas de teatro, estas passaram a ocupar espaços significativos no cotidiano dos participantes, atribuindo-lhes novos sentidos e mudanças em suas rotinas, como foi possível perceber na fala de $\mathrm{N}$. ao receber a pesquisadora:

N.: Fia, hoje eu tomei banho mais cedo e não fui ajudar na lavanderia para participar do teatro.

\section{Compreensão do abstrato e Comunicação}

No início do trabalho, jogos teatrais que envolviam compreensão do abstrato, comunicação não verbal e integração grupal - tais como desatar o nó formado pelas mãos entrelaçadas e a Máquina de Ritmos ${ }^{12}$ - foram pouco ou não desenvolvidos por algumas participantes.

Durante as atividades que envolviam linguagem verbal, memória e criatividade, os participantes referiam grande dificuldade. Para tanto, foram propiciadas vivências relacionadas a outras linguagens artísticas, como exibição de filmes e improvisações, escutar e interpretar músicas, relatar vivências e criar histórias.

Partindo do pressuposto que grupos são ricos espaços de produção de subjetividades, as atividades com graus de complexidades de raciocínio foram repetidas, reproduzidas, interpretadas e improvisadas coletivamente, produzindo um movimento de internalização do âmbito grupal para o subjetivo ${ }^{14}$.

\section{Envolvimento e Concentração}

Os fatores relacionados a esta temática estavam vinculados a questões internas do grupo, como a dispersão de alguns participantes devido a fatores externos e também fatos do cotidiano que afetavam as relações, como dificuldades de relacionamento. Observou-se a predominância de alguns aspectos da internalização da antiga rotina institucional, por exemplo: o cumprimento de horários das medicações, em que os participantes retiravam-se repentinamente da sala.

Em algumas oficinas, atividades físicas mais intensas foram utilizadas como recursos de aquecimento, permitindo a diminuição da ansiedade do grupo, sendo citado por RR. como positivo:

\section{RR.: Melhor, porque ativa mais a cabeça, né!}

O compromisso dos participantes com o dia e horário da oficina, bem como o envolvimento dos mesmos, foi construído ao longo dos encontros. Pôde-se observar crescimento gradual e adesão do grupo frente às oficinas, expressos na apresentação final, construída coletivamente e de forma ativa e propositiva.

\section{Expressão corporal}

A experimentação consciente de atividades naturalizadas no cotidiano, como caminhar, falar, expressar sentimentos, escutar, foram apontadas pelos participantes como desafios. Desta forma, utilizou-se diferentes formas de suporte e acompanhamento, dentre essas: estímulos verbais, demonstração e apresentação de modelos, apresentação de técnicas corporais e vocais para facilitar a ação. Grande parte das atividades corporais foi desenvolvida individualmente num primeiro momento e, após ser internalizada, realizouse conjuntamente, o que se mostrou fundamental, pois, além do resultado qualitativo, aqueles que possuíam mais facilidade eram tidos como referência para o grupo, assumindo também a função de suporte.

Experimentações estéticas em jogos de ritmos, como A orquestra e seu diretor ${ }^{12}$, e jogos de imagens enriqueceram o repertório de movimentos e incentivaram a experimentação de novas possibilidades corporais e de comunicação.

\section{Processo de construção coletiva e Apresentação final}

Desde o início foi colocada aos participantes a ideia de uma construção coletiva que refletisse o processo de trabalho do grupo, a qual foi sendo delineada conforme o grupo se apropriava daquele espaço.

Em um dos encontros foi exibido o filme $I$ Clowns $^{15}$, a fim de que relacionassem este às vivências corporais, e deu-se início à elaboração da apresentação 
final pelos participantes. N. propôs a construção de uma peça relacionada à temática circense, então iniciou-se o processo de construção das personagens e a troca de experiências de vida entre os participantes.

Junto a cada participante, foi confeccionado um objeto cênico referente a sua personagem, tendo como propostas a facilitação do processo criativo de construção da personagem, desenvolvimento de responsabilidade e cuidado com suas individualidades.

De acordo com Boal ${ }^{13}$, a construção de um personagem implica que o ator realize buscas internas, e, no decorrer deste processo, é possível o encontro e a descoberta de habilidades e características até então ocultas no inconsciente ${ }^{13}$. Nesse sentido, pode-se verificar que esse processo facilitou o autoconhecimento e uma nova percepção da própria realidade pelos sujeitos participantes.

Um dos ensaios foi baseado no Teatro Imagem ${ }^{13}$, no qual foi proposto que cada participante apresentasse sua personagem por meio de gestos e/ou sons marcante; em seguida, os demais participantes foram convidados a trocar e experimentar outras personagens de forma que colocasse sua percepção sobre o outro; com isto foi possível agregar novos elementos às personagens. Com o desenvolvimento desse jogo, ficou evidente que alteridade e percepção grupal, aparentemente tão difíceis de serem trabalhadas inicialmente, haviam se desenvolvido com as oficinas.

Conforme cada personagem se construía, o grupo buscava uma forma de contar uma história que as relacionasse, necessitando de auxílio para ressignificar esteticamente o processo de trabalho e incorporar também os desafios e as superações dos mesmos. Ao final das oficinas e durante a preparação para a apresentação, as tarefas organizativas também se tornaram responsabilidade coletiva.

A produção final foi apresentada para estudantes, funcionários e docentes de uma universidade. Em seguida, o grupo foi convidado para realizar a abertura de um evento científico.

Rotelli $i^{5}$ aponta a necessidade de trabalhos que extravasem os muros dos hospitais, experiências inovadoras que criem espaços de produção e reprodução da vida, capazes de romper com o estigma da loucura e que, por fim, reconstruam sujeitos históricos, ou seja, aqueles que tomam a frente da própria vida de forma consciente e que compreendam a potencialidade intrínseca a todo ser humano de transformar e ser transformado pelo meio em que vive.

Essas novas experiências sociais se mostraram significativas e com potencial transformador, dando início a uma reflexão sobre os diferentes papéis que poderiam ocupar na sociedade.

\section{Entrevistas finais}

Após essas apresentações, realizou-se o encerramento do trabalho, no qual o grupo fez uma retrospectiva, e em seguida foram questionados sobre a importância do trabalho. Em resposta, foi ressaltado o movimento referente às alterações da rotina, como referiu CL:

\section{CL.: Bom fazer alguma coisa que mexe com a cabeça da gente.}

Os participantes foram questionados sobre o processo que experienciaram, e as respostas expressaram a satisfação em relação aos resultados, bem como a importância de atividades que, segundo os mesmos, conferiram novos significados e movimento às suas vidas. Entre os relatos, foi destacada a importância de resgatar memórias do período anterior à institucionalização, a mudança de rotina provocada pelas oficinas, o rompimento com a ociosidade e o sedentarismo, e a possibilidade de diversão.

\section{DISCUSSÃO}

No processo de institucionalização, as dimensões singular e particular dos sujeitos são cerceadas por meio de rotinas impostas, punições por "desordem", impossibilidade de escolhas e tomadas de decisão, constituindo tentativas de homogeneização e normalização destes sujeitos ${ }^{16,17}$. Contudo os movimentos subjetivos de resistência a essa anulação estão sempre presentes ${ }^{18}$.

Para tanto, é necessário ao processo de desinstitucionalização construir espaços de socialização, expressão e produção artística, pois estes promovem trocas materiais e afetivas, produção e ressignificação do cotidiano, de forma que cada sujeito possa também desenvolver seu potencial estético ${ }^{19}$.

Pôde-se verificar que os participantes, mesmo inseridos em um SRT, ainda apresentam traços marcantes de suas trajetórias institucionais. Nesse sentido, ao compreender que a linguagem artística propicia novos processos de comunicação, iniciou-se um processo de abertura criativa $^{20} \mathrm{e}$ de possibilidades de experimentações e vivências.

Por apresentar outras possibilidades de comunicação, o teatro como recurso terapêutico ocupacional permitiu e facilitou a experimentação de novas formas de expressão além das cotidianas ${ }^{21}$. Fazer teatro conduz também ao desenvolvimento de habilidades corporais e à busca por outras formas de comunicação. 
Contudo apropriar-se de si implica (re)educar os sentidos e a percepção, pois a comunicação ocorre por meio de sons, imagens e palavras ${ }^{22}$. O corpo é compreendido como um lugar de registros das experimentações e vivências, conscientes e inconscientes, no qual transitam os aspectos subjetivos e objetivos de nossas vivências ${ }^{19}$.

A combinação de diferentes linguagens artísticas possibilitou trabalhar aspectos da imaginação e da percepção, elementos essenciais aos processos criativos ${ }^{23}$. Nesse sentido, Boal ${ }^{13}$ traz em sua teoria que o espaço estético é como um espelho dicotômico e dicotomizante, ou seja, no palco é possível ver-se vendo, refletir sobre uma situação e experimentar sobre o impossível.

Este trabalho pôde contribuir com a superação das dificuldades ao favorecer que o sujeito se posicionasse de forma criativa e espontânea durante as atividades, trabalhando a autoestima e autoconfiança, aprendendo a lidar com a ansiedade e com a convivência em grupo, desafios característicos da desinstitucionalização ${ }^{24}$.

A Terapia Ocupacional na interface com a arte pode propiciar novas experiências sociais, observar diferentes formas de produção de vida, vivenciar situações novas e significativas, em contextos da vida social, o que facilita reflexões, e, assim, a vivência artística pode ser transposta para a existência ${ }^{20}$.

\section{CONSIDERAÇÕES FINAIS}

O uso terapêutico do teatro como recurso de intervenção terapêutica ocupacional na reinserção social de usuários de um SRT apresentou potencialidades ao proporcionar a esses a experimentação e reinvenção de seus modos de (re)produção de vida. As oficinas de teatro constituíram breves espaços de distanciamento do cotidiano cristalizado pela institucionalização, favorecendo aos usuários a apropriação de sua potência criativa, conduzindo-os a possíveis redescobertas de si mesmos.

Dessa forma, as oficinas de teatro contribuíram significativamente com o processo de (re)construção das subjetividades dos usuários, conferindo às potencialidades do uso terapêutico e estético da arte do teatro como possibilidade terapêutica ocupacional no processo de reinserção social dos usuários de um SRT.

Assim, este trabalho reafirmou a potencialidade que as experiências estéticas possuem em (re)educar os sentidos e a consciência, mediando a relação entre sujeito e mundo. A arte do teatro pode transitar entre diferentes linguagens artísticas, o que se mostrou enriquecedor nesta proposta, pois, além de referências para o desenvolvimento das atividades propostas, passaram a fazer parte do cotidiano das participantes.

A mesma arte, ao possibilitar a reinvenção do modo de vida, se entrelaça à Terapia Ocupacional, que possibilita suporte à superação dos conflitos e contradições que emergem em processos criativos e expressivos. Nesse sentido, ambas confluem para o mesmo fim: possibilitar aos sujeitos oportunidades de se (re)criarem enquanto protagonistas de suas próprias histórias.

\section{REFERÊNCIAS}

1. Brasil. Ministério da Saúde. Secretaria de Atenção à Saúde. Saúde mental. Brasília: Ed. MS; 2013 (Cadernos de Atenção Básica, 34). Disponível em: http://bvsms.saude.gov.br/bvs/ publicacoes/cadernos_atencao_basica_34_saude_mental. pdf.

2. Rios CSL. Luta antimanicomial e cidadania. Ata Cidadania; 2007. Disponível em: http://www.atacidadania.org.br/ artigos/artigo.php?idqtd $=5 \& \mathrm{id}=8$.

3. Brasil. Ministério da Saúde. Secretaria de Atenção à Saúde. Departamento de Ações Programáticas Estratégicas. Residências terapêuticas: o que são, para que servem. Brasília: Ministério da Saúde; 2004.

4. Brasil. Ministério da Saúde. Portaria GM no . 106, de 11 de fevereiro de 2000. Brasília; 2000.

5. Rotelli F. A instituição inventada. In: Nicácio MFS, organizadora. Desinstitucionalização. São Paulo: Hucitec; 1990. p.89-100.

6. Francisco BR. Terapia ocupacional. 2a ed. Campinas: Papirus; 2001.

7. Mecca RC, Castro ED. Epifania do acontecer poético: aspectos da experiência estética na relação sujeito-obra em terapia ocupacional. Rev Ter Ocup Univ São Paulo. 2009;20(3):180-7. DOI: http://dx.doi.org/10.11606/ issn.2238-149.v20i3p180-187.

8. Minayo MCS. Pesquisa social: teoria, método e criatividade. 22a ed. Rio de Janeiro: Vozes; 2003.

9. Minayo MCS. O desafio do conhecimento: pesquisa qualitativa em saúde. 8a ed. São Paulo: Hucitec; 2004. 
10. Spolin V. Jogos teatrais: o fichário de Viola Spolin. 2a ed. São Paulo: Perspectiva; 2006.

11. Spolin V. O jogo teatral no livro do diretor. São Paulo: Perspectiva; 1999.

12. Boal A. 200 exercícios e jogos para o ator e não-ator com vontade de dizer algo através do teatro. 5a ed. Rio de Janeiro: Civilização Brasileira; 1985.

13. Boal A. O arco-íris do desejo: método Boal de teatro e terapia. 2a ed. Rio de Janeiro: Civilização Brasileira; 2002.

14. Barros RD. Benevides, grupo e produção. In: Iancetti A, organizador. Saúde loucura n.4 - grupos e coletivos. São Paulo: Hucitec; 1993.

15. Fellini F. I Clowns [filme]. Itália: editor; 1970. DVD $92 \mathrm{~min}$.

16. Heller A. O cotidiano e a história. 4a ed. Rio de Janeiro: Paz e Terra; 1992.

17. Heller A. Sobre el concepto abstracto de vida cotidiana. In: Heller A. Sociología de la vida cotidiana. 3a ed. Barcelona: Ediciones Península; 1991. p.19-90.

18. Torre EHG, Amarante P. Protagonismo e subjetividade: a construção coletiva no campo da saúde mental. Rev Ciênc
Saúde Coletiva. 2001;6(1):73-85. DOI: http://dx.doi. org/10.1590/S1413-81232001000100006.

19. Mângia EF, Muramoto M. Redes sociais e construção de projetos terapêuticos: um estudo de serviço substitutivo em saúde mental. Rev Ter Ocup Univ São Paulo. 2007;18(2):54-62. DOI: http://dx.doi.org/10.11606/issn.2238-6149.v18i2p54-62.

20. Castro ED, Silva DM. Habitando os campos da arte e da terapia ocupacional: percursos teóricos e reflexões. Rev Ter Ocup Univ São Paulo. 2002;13(1):1-8. DOI: http://dx.doi. org/10.11606/issn.2238-6149.v13i1p1-8

21. Galvanese ATC. A produção do cuidado através de atividades de arte e cultura nos Centros de Atenção Psicossocial CAPS/ Adultos do município de São Paulo [Dissertação]. São Paulo: Faculdade de Medicina, Universidade de São Paulo; 2010.

22. Boal A. A estética do oprimido. Rio de Janeiro: Garamond; 2009.

23. Dorfles G. O devir das artes. São Paulo: Martins Fontes; 1992.

24. Silva SP. O teatro como proposta de recurso na Terapia Ocupacional visando a aplicação na clínica da farmacodependência. São Paulo: Centro Universitário São Camilo; 2003. 